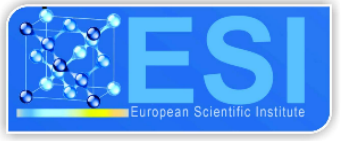

10 years ESJ

Special edition

\section{Stefania Cicillini}

University of Torino

\section{Antonella Giacosa University of Torino}

Submitted: 03 August 2020

Accepted: 20 November 2020

Published: 23 December 2020

Corresponding author:

Stefania Cicillini

DOI: $10.19044 /$ esj.2020.v16n38p46

(c) Copyright 2020 Cicillini, S. Distributed under Creative Commons BY-NC-ND 4.0 OPEN ACCESS

\section{Cite as:}

Cicillini, S. and Giacosa, A. (2020). EnglishMedium Instruction (Emi) Lecturers' And Students' Perceptions About The Transition From In-Person To Emergency Remote Education (Ere). European Scientific Journal, ESJ, 16(38), 46.

https://doi.org/10.19044/esj.2020.v16n38p46
English-Medium Instruction Lecturers' and Students' Perceptions about the Transition from in-Person to Emergency Remote Education

\section{Abstract}

Due to the COVID-19 emergency lecturers and students had to become familiar with online education and had to interact and communicate digitally to replace face-to-face interaction. In this context Emergency Remote Education (ERE) emerged, a branch of distance learning concerning the unplanned response to an educational emergency. This task was particularly challenging for students and lecturers involved in English-medium instruction (EMI) degree programmes, which are completely taught in English, have a diverse student population and are often characterized by issues relating to English proficiency, interaction and communication.

This paper, in which EMI merges with ERE, addresses how lecturers and students of EMI courses in "Medicine and Surgery" and "Nursery" from several Italian universities have coped with the sudden changes in the teaching mode due to the passage from classroom to screen. Both quantitative and qualitative data are collected through questionnaires filled in by lecturers and students of EMI degree programmes taught in 14 Italian universities. On the one hand, they show the changes EMI courses of "Medicine and Surgery" and "Nursing" underwent during the lockdown and the lecturers' and students' satisfaction concerning interaction and ERE classes. On the other hand, they help identify key elements and strategies, which can contribute to improve EMI remote education so that it is promoted from ERE to quality distance 
learning.

Keywords: EMI, English-Medium Instruction, Emergency Remote EMI, English-Medium Instruction, Emergency

Remote Education, Online Learning, Higher Educatiom

\section{Introduction}

In March 2020 the whole education system in Italy was suddenly forced to migrate onto digital platforms due to the coronavirus emergency: lecturers and students had to interact and communicate digitally to replace face-to-face interaction. This task has been particularly challenging for students and lecturers involved in English-medium instruction (EMI) degree programmes, where the use of a foreign language to teach and learn is a key issue to guarantee high quality standards. Indeed, English proficiency, interaction and communication are major challenges for the success of EMI programmes in Italy (Costa and Coleman, 2013; Pulcini and Campagna, 2015), especially in certain unusual circumstances, such as the remote learning education during the COVID-19 emergency.

This study focuses on the "Medicine and Surgery" and "Nursing" degree programmes offered in Italy, where the EMI remote education has been very challenging due to the diverse student population, composed of both local and international students, the different linguistic backgrounds and the need for human contact between students, lecturers and patients as well.

This paper deals with the EMI teaching mode with reference to Emergency Remote Education (ERE), a branch of distance learning, defined by Bozkurt et al. (2020:2) as follows: "Emergency remote education is about surviving in a time of crisis with all resources available, including offline and/or online". Distance education is an option which relies on planning, theoretical and practical knowledge and consolidated models (Ko and Rossen 2017, Ossiannilsson et al. 2017, Rennie and Smith 2019); by contrast, ERE is a necessity change to respond to an emergency (Bozkurt et al. 2020). As EMI has risen steadily in the last two decades in Italy (Wächter and Mainworm, 2014; Broggini and Costa, 2017, Cicillini forthcoming) despite the concern on the generally low levels of English proficiency, hindered interaction and understanding and possible impoverishment of quality standards, this study aims at investigating a field of increasing future interest with reference to academic teaching and learning.

Although the collected data shows that the sudden shift to digital platforms has been critical for a degree course requiring constant exposure to 
the foreign language and oral interaction, both lecturers and students have been able to respond to the emergency successfully and are on the whole satisfied with the exam results. Nonetheless, their perceptions of the difficulties and challenges they had to face in remote teaching and learning give an interesting insight into ERE for EMI degree courses, which could contribute to improve EMI education so that it can be promoted from a necessity choice to quality distance teaching and learning.

The first part of the present paper will introduce the research questions, and the methodology used to gather data and shape the analysis. In the second part, data will be presented and trends concerning EMI attitudes during the emergency will be identified referring to both lecturers and students. In the third part, the challenges and opportunities for EMI teaching and learning during the Covid-19 emergency will be discussed to provide an insight into emergency remote education for this field of study.

\section{Research questions and methodology}

The main aim of this study is to investigate how students and lecturers have coped with the challenges posed by the shift from face-to-face to online classes. It focuses on how lecturers and students have responded to the emergency with reference to interaction, perceptions, challenges, and opportunities, during the academic year 2019/2020. With this in mind, this research seeks to answer the following research questions:

RQ1: With reference to the EMI degree programmes in "Medicine and Surgery" and "Nursing", how did the coronavirus emergency affect the lecturers' and students' perceptions and interaction?

RQ2: What are the key factors that could turn ERE response into digital quality EMI courses?

In order to investigate these issues, data was gathered from two online questionnaires, the first addressed to the lecturers and the second to the students. By combining both quantitative and qualitative data collected from the participants' answers to closed-ended questions and their comments, we gained insight into their experience of the transition from face-to-face to online EMI education.

\section{Sample:}

The institutions identified for the study were selected according to the data available on the online database Universitaly ${ }^{l}$ managed by the Italian Ministry of Education, University and Research (MIUR). The fourteen Italian institutions involved in the survey are located in different parts of

\footnotetext{
${ }^{1}$ https://www.universitaly.it/index.php/ - Last access: 09/07/2020
} 
Italy, including Torino, Bologna, Pavia, Padova, Milano (Bicocca and S. Raffaele), Humanitas (Pieve Emanuele, Milano), Roma (La Sapienza and Tor Vergata), Cattolica del Sacro Cuore (Roma) - Campus Bio Medico (Roma), Napoli, Palermo and Messina. For the purpose of this study, all the EMI degree programmes in "Medicine and Surgery" and "Nursing" offered in these universities were considered.

Several EMI lecturers (736) were contacted by email and asked to participate in the survey by filling in the lecturers' questionnaire and by inviting their students to answer the students' questionnaire. Of the participants involved, only 49 lecturers and 100 students responded.

Instruments:

The instruments set for the data collection were two online questionnaires in English which were designed using Google forms. Participants were asked by email to participate in the survey and informed of the main objectives of the study. The students' questionnaire was also shared via social network, precisely in some Facebook students' groups.

Each questionnaire was divided into three sections: the first focused on the participants' personal background (mother tongue, university, selfevaluation of English proficiency); the second focused on their academic experience before the outbreak, when the EMI classes were offered in the face-to-face modality (digital expertise, interaction, communication and linguistic strategies adopted, language improvement, overall satisfaction); the third aimed at gaining insight into the participants' experience during the outbreak, when the EMI classes were suddenly transformed into online courses (video conferencing tools used, interaction, communication and linguistic strategies adopted, difficulties encountered, overall satisfaction, best practices suggestions).

Both the questionnaires were anonymous and composed of closedended, open-ended questions and Likert-scale-based questions made up of 5 response anchors focusing on quality. Each questionnaire could be completed in approximately 15 minutes.

\section{Main findings}

The main findings provide interesting information about the lecturers' and students' profiles, their perceptions about interaction, satisfaction and challenges in both pre-Covid 19 face-to-face classes and classes during the emergency.

\section{The lecturers' questionnaire}

\section{A) Personal Background}

The participants are mainly Italian $(90 \%)$ and teach in "Medicine and Surgery" courses $(96 \%)$ and "Nursing" (4\%) degree programmes. According to their self-evaluation the majority of them are proficient users $(44 \%$ 
consider themselves as $\mathrm{C} 1$ speakers and $21 \% \mathrm{C} 2$ ) and feel confident in their language proficiency (39\% are fairly confident, $43 \%$ are very confident and $16 \%$ extremely confident). $68 \%$ have been teaching EMI courses for 1 to 5 years, $27 \%$ for $6-10$ years and, $6 \%$ for more than 11 years. As regards their digital skills, before the emergency $31 \%$ felt fairly familiar with technology, $34 \%$ felt very familiar, $20 \%$ felt extremely familiar, whereas only $10 \%$ felt somewhat or not familiar at all.

\section{B) Academic experience before the outbreak}

\section{Perceptions about online courses before the emergency}

Our data shows that before the outbreak lecturers had a mild interest in online learning: only $18 \%$ had a positive opinion, whereas $14 \%$ of the sample had never had the chance to think about online courses, $37 \%$ had a negative opinion about them, considering them inadequate, ineffective and lacking human warmth. $18 \%$ considered them useful in case of emergency and as optional courses, but not as effective as for face-to-face classes, given the need for practical skills to be trained in laboratories.

\section{Interaction during face- to- face classes}

English is used as a lingua franca by $92 \%$ of lecturers, who answered in English both to students' questions asked in English (61\%) and in Italian $(45 \%)$ to stick to the course requirements. To facilitate interaction, $68 \%$ used to ask questions and to repeat sentences in class, $38 \%$ would simplify the language or slow the speech rate, whereas only $4 \%$ used code-switching (Italian-English) and 2\% used jokes to keep the interaction going.

On the whole, the lecturers were satisfied with the level of interaction in their in-person classes: $41 \%$ of them felt very satisfied, or at least fairly satisfied $(38 \%)$ or even extremely satisfied $(14 \%)$, whereas only $8 \%$ were somewhat satisfied and $2 \%$ not at all satisfied. The reasons for their satisfaction concern the atmosphere of trust and dialogue they have experienced, the quality of class discussions about scientific articles, students' positive feedback and satisfaction, the fact that they had never experienced communication problems. By contrast, lecturers who were not satisfied with the interaction report the fact that students were less interactive than expected or were not proficient enough in English and found interaction difficult.

\section{Satisfaction with face-to-face classes}

The majority of the respondents were either very satisfied $(41 \%)$, fairly satisfied (38\%), and $14 \%$ were even extremely satisfied; on the contrary, only $6 \%$ were either somewhat satisfied (4\%) or not satisfied at all $(2 \%)$ with their face-to-face classes.

Analyzing the reasons for their satisfaction, the lecturers have mentioned the positive feedback they get from their students, the fact that 
students are motivated, interactive, knowledgeable and perform very well at exams. Furthermore, they felt satisfied because they could notice students were happy with the courses and appreciate their lecturers' efforts and activities.

On the contrary, lecturers explain their dissatisfaction with their face-to-face classes mentioning the difficulty to engage students, whose English is not good, which makes them less confident and reluctant to intervene actively.

\section{C) Academic experience during the outbreak}

As regards the experience of online classes during the outbreak, $67 \%$ of our informants taught online live classes (synchronous mode) and 6\% recorded their online classes so that students could choose when to watch them, whereas 29\% recorded video-lessons (asynchronous mode) or commented slides with audio (4\%).

With reference to time management and scheduling, most lecturers had to stick to their timetable $(60 \%)$. However, the digital mode allowed them to be more flexible: $27 \%$ declared they were able to choose when to teach classes according to their needs, some of them had longer classes to deal properly with a topic $(23 \%)$, they sometimes decided to have longer classes to deal properly with a topic $(10 \%)$ or to organize extra-lessons $(19 \%)$.

\section{Interaction, difficulties and challenges during online classes}

$96 \%$ of the lecturers used English as a lingua franca, whereas $2 \%$ chose to speak mainly English, but they translated difficult passages into Italian and another $2 \%$ provided clarifications and more detailed explanations in Italian. The majority of the lecturers answered in English $(87 \%)$, even when the question was asked in Italian and only $13 \%$ answered in Italian if the question was asked in Italian. To facilitate interaction, lecturers used repetition (80\%), questioning (48\%), simplification of language $(32 \%)$, slower speech rate $(43 \%)$, code-switching $(5 \%)$ or other strategies such as chats and polls $(2 \%)$ and additional exercises.

Finally, concerning the interaction, only $13 \%$ were very satisfied or extremely satisfied (7\%), 27\% were fairly satisfied, whereas 33\% were somewhat satisfied and $20 \%$ were not satisfied at all. The dissatisfaction was due to the reduced interaction $(22 \%)$, difficulties in getting feedback about students' understanding (10\%), poor internet connection $(4 \%)$, difficulties in engaging students $(4 \%)$, checking attendance (4\%), organizing group works $(2 \%)$. The lecturers who were satisfied with the interaction stated online courses were an interesting experience (4\%), the lessons were easy $(2 \%)$, as effective as face-to-face courses considering exam results $(2 \%)$, and there was an increased attendance rate $(2 \%)$. 
Concerning the difficulties during online classes, $47 \%$ felt they were talking into an empty space, $40 \%$ were afraid of connection problems, $29 \%$ were afraid of not being able to help students solve their technical problems, $20 \%$ felt uneasy, $20 \%$ found it difficult to carry on with the syllabus, $4 \%$ felt it was difficult to keep the interaction going.

$73 \%$ think online and face-to-face courses were not equally effective and educational, because in-person lessons were much more stimulating for students, thanks to interaction, human contact, body language, sense of community. On the contrary, $27 \%$ think face-to-face and online classes were equally effective because of similar outcomes. As regards the next academic year, $57 \%$ would like to teach in-person courses, $30 \%$ would like to teach blended courses, whereas only $13 \%$ would like to teach online courses.

\begin{tabular}{|c|c|c|}
\hline & Face-to-face classes & Emergency remote EMI classes \\
\hline Perceptions & $\begin{array}{l}37 \% \text { negative opinion } \\
18 \% \text { positive opinion } \\
18 \% \text { useful as necessity choice } \\
14 \% \text { never thought about them }\end{array}$ & $\begin{array}{l}73 \% \text { think they are not as } \\
\text { effective as } \\
\text { face-to-face classes } \\
27 \% \text { think they are as effective as } \\
\text { face-to face classes }\end{array}$ \\
\hline Interaction & $\begin{array}{l}1 \% \text { very satisfied } \\
38 \% \text { fairly satisfied } \\
14 \% \text { extremely satisfied } \\
8 \% \text { somewhat satisfied } \\
2 \% \text { not at all satisfied }\end{array}$ & $\begin{array}{l}33 \% \text { somewhat satisfied } \\
27 \% \text { fairly satisfied } \\
20 \% \text { not at all satisfied } \\
13 \% \text { very satisfied } \\
7 \% \text { extremely satisfied }\end{array}$ \\
\hline
\end{tabular}

Figure 1. Face-to-face classes and Emergency remote classes in lecturers' perception

\section{The students' questionnaire:}

\section{A) Personal Background}

Of the 100 students who filled in the questionnaire, 57 are Italian, while the others are international students who have different L1. Among these, there are also 14 English native speakers. The remaining students have different mother tongues, which are spoken in EU and non-EU countries. $92 \%$ of them are enrolled in EMI degree programmes in "Medicine and Surgery" (92\%) while $8 \%$ study in "Nursing".

Concerning their English proficiency, on average most of the students feel very confident in their language skills. $73 \%$ claim to be proficient user of the language and thus to have a C2 (32) and a C1 (41) level of English; $25 \%$ is an independent user of English and has a B2 (18) or a B1 (7) level of English. Only $2 \%$ of the respondents self-evaluate themselves as basic users, with A1 (1) and A2 (1) levels of English.

As regards their digital expertise, roughly $60 \%$ of the students were already familiar with digital educational platforms such as Moodle before the pandemic, while $40 \%$ of them had to learn how to use such platforms during the emergency. After the pandemic, $78 \%$ of them confirmed to feel very confident in the use of the digital tools proposed. In addition, whereas only 
$25 \%$ of the respondents had attended online courses before the emergency, the majority $(75 \%)$ began their digital experience during the outbreak.

\section{B) Academic experience before the outbreak}

\section{Communication and interaction in face-to-face classes}

As for the institutional communication and the notice boards mostly used by the departments before the coronavirus emergency, $48 \%$ of the students claimed the use of Moodle, followed by Microsoft Teams (13\%), the department websites (13\%), e-mails (6\%) and Kiro platform (5\%).

When they were asked to express their opinions on the interaction taking place in face-to-face classes, $45 \%$ of them were very satisfied, $34 \%$ fairly satisfied while $21 \%$ were not satisfied at all.

\section{Students' perceptions and satisfaction}

As regards their overall English level, 38\% reported some improvements in their English proficiency, especially in the general and medical terminology. Most of them think that communication and interaction in class, both with peers and lecturers, led them to improve their English skills unconsciously.

$43 \%$ think that they did not improve their language skills during the face-to face EMI classes while 19\% is not aware of any possible language improvement. Indeed, some students claimed to have very high levels of English proficiency because they used to live in English-speaking countries, studied English as a foreign language (EFL) or experienced CLIL ${ }^{2}$ classes at school for several years. As a consequence, they think that their language competence has not changed but in some cases has worsened. Others complained about the overall low levels of English proficiency and poor accents in their EMI classes, both in lecturers and classmates.

\section{C) Academic experience during the outbreak}

\section{Communication and interaction in online classes}

During the outbreak, students attended classes through different tools which included: Zoom (41\%), Microsoft Teams (20\%), WebEx (18\%), prerecorded ppts $(12 \%)$, Google meet $(7 \%)$ and blended tools $(2 \%)$. During the online classes, most of the students could listen and take notes at the same time (59\%), ask questions (48\%) and interact while just a few could check the dictionaries when necessary. When they were asked about interaction in class, some of them claimed that they used questions and repetitions; when necessary they repeated and reformulated their questions, spoke slowly or used the chat because they did not feel confident about their English

\footnotetext{
${ }^{2}$ CLIL is an acronym that stands for 'Content and Language Integrating Learning' and refers to that educational settings, mostly at primary and secondary levels of education, where teachers teach both the subject content and the language being used for instructional purposes.
} 
proficiency. When they needed clarifications, most of them asked a friend for help or wrote emails to their lecturers $(80 \%)$ while just a few used the forum (20\%).

\section{Students' perceptions, satisfaction and challenges}

On the whole, students are slightly satisfied with the level of interaction during the online classes which took place mostly in English, both in oral and written form. $44 \%$ of them were very satisfied with the quality of education, $19 \%$ fairly satisfied whereas $37 \%$ were not satisfied at all.

As regards their English proficiency, most of the respondents (56\%) argued that their language competence did not improve. The main causes expressed by the students encompassed: lecturers' low level of English proficiency; too many pre-recorded ppts and materials instead of online classes; poor interaction and communication; low practice and human contact. The remaining 20\% of students think that their English proficiency improved while $24 \%$ is not sure. In their opinions, the improvement may have been facilitated by the online interaction with lecturers and course mates and the self-study at home during the emergency.

The majority of the students claimed to have attended boring lessons during the emergency although they considered them easier than face-to-face classes. Overall, 67\% argued that accessing lessons and materials was easy although keeping up with the pace of the lesson was more difficult because of internet connection problems (72\%) and lecturers' accents $(27 \%)$. In addition, other students (13\%) complained about their limited access to computers because they did not have a personal computer and had to share it with others or even study through their mobile phones.

Much concern has also been expressed about the unclear modalities of online exams, the insufficient quality of materials and lessons and the impossibility to study with classmates. When they were asked what they missed most about the face-to-face classes, the majority answered that they missed live classes, human contact and interaction with lecturers and patients and campus life. Nevertheless, 51\% would like blended EMI courses for the next academic year, whereas $32 \%$ would prefer face-to-face classes and $17 \%$ would continue with the online modality only. 


\begin{tabular}{|l|l|l|}
\hline & Face-to-face classes & $\begin{array}{l}\text { Emergency remote EMI } \\
\text { classes }\end{array}$ \\
\hline Interaction & $\begin{array}{l}45 \% \text { very satisfied with the } \\
\text { quality of the courses; 34\% } \\
\text { fairly satisfied; 21\% not } \\
\text { satisfied }\end{array}$ & $\begin{array}{l}\text { 44\% very satisfied with the } \\
\text { quality of the courses; 19\% } \\
\text { fairly satisfied; 37\% not } \\
\text { satisfied }\end{array}$ \\
\hline $\begin{array}{l}\text { Digital } \\
\text { expertise }\end{array}$ & $\begin{array}{l}60 \% \text { familiar with digital } \\
\text { tools } \\
40 \% \text { not familiar with } \\
\text { digital tools }\end{array}$ & $\begin{array}{l}78 \% \text { very confident using } \\
\text { digital tools } \\
22 \% \text { fairly confident with } \\
\text { digital tools }\end{array}$ \\
\hline $\begin{array}{l}\text { English } \\
\text { proficiency } \\
\text { improvemen } \\
\mathrm{t}\end{array}$ & $\begin{array}{l}43 \% \text { think they did not } \\
\text { improve } \\
38 \% \text { think they improved } \\
19 \% \text { are not aware }\end{array}$ & $\begin{array}{l}56 \% \text { think they did not } \\
\text { improve } \\
20 \% \text { think they improved } \\
24 \% \text { are not aware }\end{array}$ \\
\hline
\end{tabular}

Figure 2. Face-to-face classes and emergency remote classes in students' perception

\section{Discussion and conclusions}

\section{Profiles based on personal backgrounds}

To have an insight into the effects of ERE on EMI courses, first the lecturers' and students' profiles emerging from our data collection will be described. On the one hand, as it is shown in the previous section, both EMI lecturers and students evaluate themselves as proficient speakers: $64 \%$ of the lecturers and $75 \%$ of the students define their level as $\mathrm{C} 1-\mathrm{C} 2$ and $98 \%$ of the informants of both groups claim to be confident in their linguistic skills, even if several language issues have been mentioned in their comments. Moreover, $56 \%$ of the students do not think their English improved during online lessons because either they are native speakers, or they feel they are more proficient than their lecturers.

On the other hand, both groups show different degrees of familiarity with the digital platforms: although $81 \%$ of the lecturers felt familiar (even if at different levels) with the technology before the emergency, $60 \%$ of the students knew how to use Moodle and $75 \%$ of them had never attended an online course before. Moreover, $72 \%$ of the students reported poor internet connection as a major problem they had to face during the lockdown.

Therefore, in the lecturers' and students' perceptions ERE has not been an issue of great concern for linguistic skills, but it has shown a 
significant perceived digital divide which will have deeply affected mostly students and needs to be addressed in case of a new emergency.

\section{Interaction and satisfaction}

Before the emergency - face-to-face classes

Before the pandemic, universities offered their EMI classes through the face-to-face modality and much of the institutional communication was facilitated by the use of certain digital tools such as the department websites, lecturers' pages, emails and the Moodle platform. On the whole, both students and lecturers claimed to be satisfied with the quality of education and the overall interaction in their EMI classes. While lecturers mostly appreciated the constant contact, feedback and communication with students, they also encountered difficulties in engaging students and promoting interaction in class. Undoubtedly, engagement and interaction are key factors for of academic courses, especially when they are taught through a foreign language, as in the case of EMI programmes (Dafouz and Sánchez García, 2013; Johnson and Picciuolo, 2020).

To facilitate interaction, most of the EMI lecturers sampled used certain linguistic strategies such as questioning, repetitions and simplification of language. Nevertheless, the low levels of English proficiency, expressed by the respondents, may have influenced the quality of interaction, as also confirmed in previous studies on EMI (Shohamy 2013; Drljača Margic and Vodopija-Krstanovic, 2018). Although the majority of the respondents self-evaluated themselves as proficient $(\mathrm{C} 1-\mathrm{C} 2)$ and independent (B1 - B2) users of English, their answers suggested that the English self-evaluation may have been overestimated and that much attention should be paid to the stakeholders' initial language competence. Finally, alternative ways for engaging students in class are required together with the need to develop communication skills which may encourage meaningful interaction in EMI classes.

During the emergency - online classes

The EMI lecturers involved in this survey seem to have used similar linguistic strategies to those used in face-to-face classes (questioning, repetitions, simplification of language, slower speech rate) and exploited the potentialities of the online modality (use of chatbox, blogs and different online platforms, more flexibility and less embarrassment) during the emergency. Notwithstanding their efforts, both students and lecturers are less satisfied with the level of interaction in the online classes, compared to the face-to-face modality. Especially in those asynchronous EMI classes offered by some lecturers, which have been widely criticized by the students because of the inconsistency of certain materials and the impossibility to interact and ask for clarifications. In the case of the asynchronous modality, additional 
strategies may be taken into account in order to foster interaction and allow mobile learning, such as videos, hyperlinks, interactive pdfs and personalized feedback, as also suggested by Cicillini and Salusso (2019).

On the whole, possible explanations of this general dissatisfaction may be related to the lack of clear communication and instructions, partly due to low levels of English proficiency and of digital expertise, to the difficulties to combine the online learning with the EMI demands and to the lack of human contact, especially with patients. Moreover, lecturers complained about the difficulties of collecting feedback through body language, eye contact and interaction, which could have provided information about students' general understanding and reactions.

Finally, the results provide further support for the hypothesis that in a demanding environment such as the EMI online learning, much attention should be paid to language competence, digital expertise, strategic communication and institutional support, both to students and lecturers.

\section{Challenges, perceptions and future perspectives}

With reference to the first research question of this study concerning the influence of the emergency on EMI students and lecturers of "Medicine and Surgery" and "Nursing" degree programmes, the collected data shows an increase in students' digital literacy: before the coronavirus emergency, roughly $60 \%$ felt familiar with educational technology which rocketed to $98 \%$ after the lockdown. However, students were deeply affected by the digital divide: if both lecturers and students reported connection problems and would benefit from improvements in the internet access in case of new emergencies, data shows students were the most affected: $13 \%$ of them had to share their devices or attended their courses using their mobile phones. Therefore, concerning the second research question referring to the key factors that could turn ERE response into digital quality EMI courses, in case universities have to deliver distance education in the next academic year, they have to put in place resources to address the digital divide.

Regarding the emotional issues due to the COVID-19 emergency, the isolation and lack of human contact took a toll on students and lecturers: $47 \%$ of the lecturers lamented during online classes they felt like talking into an empty space and were afraid of connection problems (40\%), and of not being able to help students solve their technical problems (29\%). Students missed human contact not only with their classmates but also with patients and lecturers. Thus, in case of new emergencies the issue of transactional distance has to be distinguished from the spacial distance (Bozkurt et al. 2020: 3): on the one hand, safe spacial distance must be kept, on the other hand, support communities for both lecturers and students have to be built. Furthermore, lecturers need to implement well-being and care literacy to 
support their students' emotional needs, which play a key role under these circumstances (Bali 2020: 4).

Concerning the changes in lecturers' perceptions of online courses, before the emergency only $36 \%$ of the lecturers were in favour of online teaching: $18 \%$ had a positive opinion about them, whereas another $18 \%$ considered them useful but only during an emergency or as subsidiary courses. This widespread distrust of online education can be explained with the fact that $94 \%$ of the lecturers were satisfied with face-to-face classes. In their comments, they reported a general lack of trust in the effectiveness of elearning due to the lack of interaction and direct feedback. Comparing this data with the lecturers' opinion about online courses during the emergency, ERE seems not to have changed their mostly negative opinion. Despite some positive comments about the outcomes of emergency remote teaching, 57\% of the lecturers would like to teach in-person EMI courses during the next semester, whereas only $13 \%$ of them would rather have online courses.

It is interesting to see that students show a partly different idea about online courses: even if they experienced connection problems and difficulties in accessing materials and keeping up with the pace of the courses, still only $32 \%$ of them would like to attend face-to-face courses in the next term. $51 \%$ of the students would opt for blended courses: even if they missed the interaction with their peers, they found it easier (and cheaper) to study from home. However, both lecturers and students highlight the need for training and technical support to exploit the full potential of EMI courses and digital platforms. On the one hand, despite the perceived proficiency and confidence in English, both students and lecturers have suggested that misunderstandings and shortcomings were due to insufficient language competence, which was further affected by the lack of interaction.

Thus, in case of new emergencies, issues concerning linguistic proficiency and interaction should be addressed, which by the way would be advisable also in the face-to-face modality. On the other hand, better digital literacy and flexibility of the digital platforms and the uploaded pre-recorded materials would be necessary for effective distance teaching and learning. Consequently, support, care and planning are three major factors academic pedagogy has to rely on to transform ERE into remote learning.

Data referring more specifically to the research question about the key factors that could turn ERE response into digital quality EMI courses shows that, in case university teaching should shift again to the online, several good practices are envisaged by both the lecturers and students: besides training and support, they suggest planning and common guidelines and an increase in recorded lessons. Students recommend that lecturers increase interaction, encourage discussion groups thanks to better platforms 
and new technologies. Lecturers hope students can rely on better connections to be able to keep their cameras on and interact more.

$43 \%$ of our respondents are international students, who according to our expectations would report difficulties concerning the attendance of virtual classes from their home countries, maybe in different time zones, or being far away from their families during an emotionally stressful time. However, our data does not show significant differences between local and international students. Therefore, we believe that further research on the needs of international students and more widely on EMI students is necessary to identify the issues of concern to address in case of a new emergency.

In conclusion, issues such as language proficiency and poor interaction which affected emergency learning are similar to those typical of EMI face-to-face classes. Thus, further research and resources are needed to improve the quality and effectiveness of both online and in-person EMI courses. However, this study has revealed that in case of emergency lecturers and students not only responded but the majority of them succeeded in reaching their goals and improved their skills. Thus, improvements concerning the digital divide, the exposure to the foreign language, the human relationship with classmates and patients, the attention to

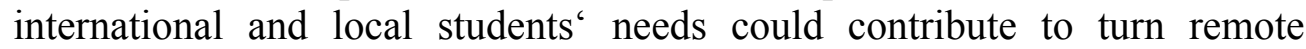
emergency EMI courses for "Medicine and Surgery" and "Nursing" into quality distance education. After all, as a lecturer commented, online learning is a possibility, which has been offered for years by internationally renowned medical schools around the world, so it might be worth trying to exploit its full potential.

\section{References:}

1. Bali, M. (2020, May 13). Literacies Teachers Need During Covid-19. Al-FanarMedia. https://www.al-fanarmedia.org/2020/05/literaciesteachers-need-during-covid-19/

2. Bozkurt, A., Xiao, F., Jung, I., Vladimirshi, V. (2020). A global outlook to the interruption of education due to COVID-19 Pandemic: Navigating in a time of uncertainty and crisis, Asian Journal of Distance Education, Volume 15, Issue 1, 2020

3. Broggini, S., and Costa, F. (2017). A survey of English-medium instruction in Italian higher education. Journal of Immersion and Content-Based Language Education, 5(2), 238-264.

4. Cicillini, S. and Salusso, D. (2019). Content interaction in online university courses: the start@unito project. In HEAD'19. 5th International Conference on Higher Education Advances. Editorial 
Universitat Politècnica de València. 1197-1205. https://doi.org/10.4995/HEAD19.2019.9449

5. Cicillini, S. (forthcoming). English language entry requirements in EMI degree programmes at bachelor level in Italy.

6. Dafouz M., E., and Sanchez García, M. D. (2013). Does everybody understand?' Teacher questions across disciplines in Englishmediated university lectures: An exploratory study. Language Value, 5(1), 129-151.

7. Drljača Margic, B., and Vodopija-Krstanovic, I. (2018). Language development for EMI: Teachers' perceptions, reflections and learning. Journal of English for Academic Purposes, 35, 31-41.

8. Johnson, J. H., and Picciuolo, M. (2020). Interaction in spoken academic discourse in an EMI context: the use of questions. In HEAd'20. 6th International Conference on Higher Education Advances. Universitat Politècnica de València. 211-219. http://dx.doi.org/10.4995/HEAd20.2020.11018

9. Ko, S., Rossen, S. (2017). Teaching online. A practical guide. New York: Routledge.

10. Ossiannilsson, E., Williams, K., Camilleri, A. \& Brown, M. (2015). Quality Models in Online and Open Education around the Globe. State of the Art and Recommendations. Oslo: International Council for Open and Distance Education .

11. Rennie, F., Smyth, K. (2019). Digital Learning. They Key Concepts. London: Routledge.

12. Shohamy, E. (2013). A critical perspective on the use of English as a medium of instruction at universities. In Doiz A., Lasagabaster D. and Sierra J. M. (eds), English-medium instruction at universities: Global challenges, 196-210. Bristol/Buffalo/Toronto: Multilingual Matters

13. Wächter, B., \& Maiworm, F. (2014). English-taught programmes in European Higher Education: The state of play in 2014. ACA papers on international cooperation in education. Bonn: Lemmens. 